\title{
BOAS POLÍtICAS E MÁ ESTRATÉGIA
}

THE LOGIC OF POLITICAL SURVIVAL

de Bruce Bueno de Mesquita, Alastair Smith, Randolph Siverson e James Morrow. Cambridge, MA: MIT Press, 2003, 536 pp.

FÁbIO KERCHE E CRISTIANE CARNEIRO

Paz e prosperidade resultam do progresso econômico ou de instituições políticas que promovem o desenvolvimento? Essa pergunta resume uma parte do debate da ciência política, principalmente a norteamericana. Para os neo-institucionalistas, o mais forte elemento explicativo do sucesso ou fracasso de uma economia são as instituições. $\mathrm{O}$ livro The logic of political survival [A lógica da sobrevivência política] apresenta uma interessante e original abordagem dessa perspectiva, utilizando-se de modelos matemáticos mas sem comprometero acesso a leitores não familiarizados com essa linguagem. Partindo do pressuposto de que os homens públicos querem se manter no poder, independentemente do modelo institucional vigente em seu país, os autores se perguntam por que líderes democráticos permanecem, em média, duas vezes menos tempo no poder do que ditadores que têm como marca de governo a corrupção e a guerra.

Para responder a essa pergunta, os autores desenvolvem um modelo baseado numa série de exemplos históricos no qual propõem que o desenho institucional dos países determina a longevidade dos líderes no poder. Traços culturais e características da sociedade em questão desempenhariam papel secundário, embora os autores admitam que o grau de competência política e choques econômicos são fatores que podem ter influência no tempo de permanência do líder no poder. Para eles, os ditadores não são corruptos e os democratas altruístas em virtude de características individuais, mas sim porque as instituições produzem incentivos para que os líderes se comportem de forma democrática ou ditatorial: o modelo institucional gera "imperativos de ação para políticos que querem permanecer no cargo" (p. 9). No caso da democracia, isso induz os líderes a gerar bens públicos para a maior parte da população. Em regimes autocráticos, os líderes aumentarão suas chances de permanecer no poder se houver distribuição de bens privados para um grupo reduzido. Em outras palavras, por conta dos imperativos do modelo institucional, numa democracia é mais racional ser "bom" do que ser "mau", enquanto o oposto se aplica a um regime autocrático. 
A explicação dessa racionalidade e dos imperativos de ação dos líderes baseia-se na "teoria dos selecionadores" (selectorate theory). Segundo esse modelo, em toda sociedade há aqueles que participam do processo de escolha do líder, os selecionadores (Selectorate ou $S$ ), e entre estes há os que efetivamente contam para a sustentação do líder, formando a coalizão vencedora (Winning Coalition ou $W$ ). Em regimes democráticos o $S$ e o $W$ são numerosos, enquanto em regimes autocráticos o $W$ é reduzido e o $S$ pode variar. Assim, na União Soviética, por exemplo, embora ocorressem eleições com sufrágio bastante amplo, eram os membros do Partido Comunista que sustentavam o dirigente máximo do país. Nesse sentido, é do interesse do líder garantir benefícios aos integrantes da coalizão vitoriosa que o sustentará no governo. Quando a coalizão vencedora não é numerosa, o líder pode distribuir bens privados a esse grupo a fim de gerar um alto grau de fidelidade.

A lógica do modelo parte do pressuposto de que bens públicos são indivisíveis e de consumo não-excludente. De fato, o líder democrata somente pode remunerar a sua coalizão vencedora com bens públicos, dada a ampla dimensão dessa coalizão. Já o líder autocrático, cuja coalizão vencedora é muito menor, pode remunerar $W$ com bens privados. Esse raciocínio traz conseqüências para os processos de transição no poder. A estratégia dos líderes autocráticos consiste em construir relações de lealdade junto à sua coalizão vencedora. Do ponto de vista desta, as oportunidades de garantir o fluxo de favores e "rents" caso um novo líder chegue ao poder não são muito atrativas. Quanto maior o número de selecionadores $(S)$, menor a chance de que os membros de uma determinada coalizão vencedora continuem a fazer parte do círculo íntimo do novo líder, de modo que para $W$ também há incentivos para se manter leal ao líder no poder. Já em regimes democráticos as chances de participar de uma nova coalizão vencedora são bem maiores, dado que por definição as democracias governam para a maioria. Em muitos desses regimes a coalizão vitoriosa se aproxima de $50 \%$ dos selecionadores.

Os autores discutem a questão de lealdade de forma mais precisa mediante a análise do que chamam de "norma delealdade" (loyalty norm), que nada mais é que a razão entre WeS. Nas palavras dos autores: "Quanto menor a razão $W / S[\ldots]$, tanto menos os membros da coalizão estarão inclinados a pôr em risco benefícios privados para apoiar um oponente político do titular do poder. Assim, quando a coalizão é especialmente pequena e o grupo de selecionadores especialmente grande, como ocorre em muitas autocracias eleitas por meios fraudulentos, a lealdade dos membros da coalizão ao titular do poderéespecialmente alta" (p.68).Já no caso da democracia, a distribuição de bens privados é muito mais difícil, visto que a coalizão vitoriosa necessariamente é bastante ampla. Desse modo, o líder deve contar com a geração majoritária de bens públicos, beneficiando a todos e não somente à coalizão vitoriosa. Quando a coalizão é ampla, afirmam os autores, "diminui a diferença relativa do 
valor dos bens recebidos por aqueles que estão dentro e fora da coalizão" (p. 92). Na democracia, portanto, é menos custoso para o integrante da coalizão vitoriosa abandonar o líder e apoiar o desafiante. Assim é que a democracia gera menos fidelidade ao líder, o que explica que nos regimes democráticos os governantes permaneçam por menos tempo no poder.

Conseqüentemente, políticas macroeconômicas que gerem riqueza para toda a sociedade não são uma opção benevolente dos líderes nas democracias, mas uma imposição da instituição. Por outro lado, políticas menos distributivas - como as que envolvem corrupção e rent-seeking - são racionais em autocracias porque garantem a fidelidade da coalizão vencedora. Assim, diferentemente do que afirmam muitos economistas, políticas econômicas "equivocadas" não são necessariamente irracionais, já que podem beneficiar o grupo que apóia o líder, aumentando os custos para defecções e garantindo mais tempo de poder para o líder.

Nesse sentido, "[o] comportamento dos líderes deriva de seu próprio interesse em manter suas posições. Se isso coincide ou é compatível com o bem-estar dos cidadãos, muitos se beneficiarão" (p. 21). Portanto, o tamanho de $W$ é determinante para explicar por que regimes democráticos geram um crescimento acima da média. Mais que isso, "sistemas com coalizão vencedora mais ampla produzem maiores níveis educacionais, sistemas comerciais mais livres [...], menos corrupção [...], menos opressão e repressão e orçamentos mais equilibrados" (p. 102). Até mesmo a resolução de conflitos internacionais por meios violentos é menos comum em sistemas com ampla coalizão vitoriosa. Em suma, o tamanho de $W$, "combinado com a norma de lealdade [...], influencia diversos aspectos da vida política, tais como o dispêndio do líder e os benefícios da coalizão vencedora" (p.105).

Contudo, mesmo entre sistemas democráticos existem diferenças. Segundo os autores, regimes parlamentaristas baseados no voto distrital geram mais lealdade que sistemas presidencialistas, já que suas coalizões vitoriosas são menores que aquelas de sistemas majoritários com circunscrição nacional. Os regimes podem ser agrupados em grandes categorias (como democracia e autocracia), mas na verdade se distribuem num continuum. As variações entre o $W$ e o $S$ são importantes, pois têm conseqüências na "variação das taxas de impostos, na corrupção, na imigração e em outras importantes questões políticas que permeiam [...] governos democráticos" (pp. 72-73).

Mas se os regimes não-democráticos geram maior fidelidade e se o objetivo dos líderes é se manter no poder, como explicar a opção pela democracia em vários países? Não seria mais racional optar sempre pela autocracia? Segundo os autores, de certa forma sim: a ditadura sempre seria mais racional do ponto de vista do líder. No entanto, nem sempre cabe ao líder a escolha institucional do tipo de regime. Em determinados contextos históricos, são outros atores que têm a prerrogativa de decidir quais regras institucionais serão adotadas. A mudança institucional 
pode ser iniciada por um movimento daqueles que estão excluídos de qualquer etapa do processo político (mediante uma revolução, por exemplo); pode partir dos selecionadores que não fazem parte da coalizão vitoriosa e não desfrutam de bens privados gerados pelo regime; pode vir da própria coalizão vitoriosa ou do líder, e mesmo de inimigos externos.

É a partir do grupo que desencadeia a mudança institucional, em combinação com outras variáveis, que as amplitudes do $S$ e do $W$ serão definidas. O aparente paradoxo é que os sistemas com maior lealdade da coalizão vitoriosa são mais propensos a movimentos de revolta para modificar o regime. Afinal, a lealdade se dá pela combinação de um $W$ reduzido com um amplo $S$, o que gera um amplo leque de pessoas que não desfrutam de bens públicos ou privados gerados pelo regime. Segundo os autores, não é coincidência que sistemas desse tipo são propensos a se valer de instrumentos de repressão para refrear movimentos rebeldes. Parece ser essa combinação de alto grau de lealdade do $W$ e de repressão aos que não participam do sistema que garante maior sobrevida aos líderes de regimes autocráticos.

O livro está dividido em três partes. A primeira expõe os contornos do modelo teórico e oferece provas num apêndice. A segunda elabora aspectos importantes do modelo teórico, desenvolvendo o argumento mediante uma análise histórica e estatística. Todos os testes confirmam as predições do modelo quanto a dados agregados de crescimento econômico, de incidência de corrupção e apropriação indevida de recursos públicos, de duração de episódios de paz e de sobrevivência do líder no poder.A terceira parte aborda a questão delicada da mudança institucional, que pode ocorrer de forma endógena ou exógena.

No que diz respeito às mudanças institucionais endógenas, os autores começam por mapear as preferências institucionais de cada um dos grupos sociais que integram o modelo: os excluídos, os selecionadores, os membros da coalizão vencedora e o próprio líder. A partir dessa análise de preferências, mostram como as opções de protesto, saída e lealdade (citando Hirschman quase que literalmente) se colocam para cada um desses grupos sob determinadas realidades institucionais. $O$ resultado é uma análise detalhada dos padrões de imigração e de opressão imigração sobretudo por parte dos excluídos e opressão por parte dos líderes. Mais uma vez os testes empíricos confirmam as predições do modelo:líderes em regimes autocráticos usam a opressão de forma mais generalizada e contundente.

A discussão das mudanças institucionais exógenas analisa as motivações do líder no que diz respeito a conflitos internacionais armados. Aqui o pressuposto agrupa os objetivos de conflitos armados em duas categorias: aquisição territorial e reformas institucionais. Lançando mão de argumentos históricos e estatísticos, os autores demonstram que regimes com coalizãovencedora pequena seenvolvem predominantemente em conflitos de ambição territorial. Já regimes de coalizão ampla, como democracias, tendem a buscar objetivos institucionais 
[1] Conforme o modelo, o líder, sabendo que não poderia permanecer no poder, teria incentivos para praticar corrupção, já que não mais precisaria do apoio de sua coalizão vitoriosa. No entanto, instrumentos institucionais como o controle judicial limitam tal postura. quando participam em conflitos armados. A invasão do Afeganistão e a Guerra do Iraque ilustram o argumento do modelo.

Cabe aqui apontar uma questão não resolvida pelos autores e que pode prejudicar a comparação entre democracias (sobretudo as presidencialistas) e autocracias no que se refere ao tempo de permanência dos líderes no poder. Trata-se do limite do número de mandatos sucessivos estabelecido por vários sistemas democráticos: se nas autocracias, ou mesmo no parlamentarismo, o tempo em que o líder pode permanecer no poder não sofre qualquer limitação institucional, no presidencialismo, como o norte-americano ou o brasileiro, há regras que impedem o presidente de disputar um terceiro mandato, por exemplo․․ Há portanto uma contaminação nos dados que apontam que nas democracias os líderes permanecem menos tempo no poder do que nas autocracias. Uma solução para esse problema seria computar o tempo de permanência no poder do partido político, e não somente do presidente. No entanto, o modelo não permite tal solução, uma vez que além de partir do pressuposto do auto-interesse baseia-se na idéia de "promessas plausíveis" (credible promises). Nas palavras dos autores: "No modelo básico, as afinidades entre o líder e seus apoiadores são perfeitamente conhecidas, mas as afinidades entre os apoiadores e o desafiante são um completo mistério" (p. 277). Ou seja, não há qualquer garantia de que o partido político será fiel às suas promessas ou beneficiará os mesmos grupos $\mathrm{da}$ coalizão vitoriosa que sustentava o antigo líder.

Assim, o que garante originalidade ao modelo, seus pressupostos, limita soluções de questões importantes apresentadas pela realidade.É o preço que se paga na utilização de modelos pela ciência política. De qualquer forma, os autores dão uma importante contribuição para a compreensão do funcionamento das democracias e das autocracias, demonstrando com rigor acadêmico que as primeiras geram benefícios para a maioria da população.

FÁBIO KerChe é pesquisador da Fundação Casa de Rui Barbosa (Rio de Janeiro). Cristiane Carneiro é professora da Arcadia University (Estados Unidos). 